\title{
A Comparison of Hydrogen and Propane Fuels
}

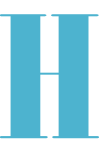

ydrogen and propane have long histories of being used as fuel. Both fuels can be used safely if their physical, chemical, and thermal properties are understood and if appropriate codes, standards, and guidelines are followed. Although the properties of hydrogen have been compared to those of propane and methane, these comparisons were made to facilitate appreciation of the physical and chemical differences and similarities among these fuels. It is not possible to rank these fuels according to safety because plausible accident scenarios can be formulated in which any one of the fuels can be considered the safest or the most hazardous.

\section{Background}

Both hydrogen and propane have been used as fuels for decades. In the 19th century, "coal gas," a mixture containing about $50 \%$ hydrogen, $26 \%$ methane, and other gases, including $7 \%$ carbon monoxide, was used extensively in Great Britain for lighting. In the United States prior to World War II, "town gas," a 50/50 mixture of hydrogen and carbon monoxide made by gasifying coal, was used by millions of Americans to cook food, light lamps, and heat water and homes. Propane was "discovered" in 1910 as a component of gasoline in a Model T Ford and was first used largely for industrial purposes, such as blowtorches to cut metals. (National Propane Gas Association, www.npga.org)

\section{Propane}

Today more than 15 billion gallons of propane are consumed annually for home, agricultural, industrial, and commercial uses. Excluding propane gas grills, residential and commercial use accounts for about $45 \%$ of this consumption. About $38 \%$ is used in the petrochemical industry as a raw material to make plastics and other items. While transportation represents the smallest sector using propane, propane is still the most common alternative transportation fuel in use today. (Propane Education and Research Council, www.propanecouncil.org)

\section{Hydrogen}

About 7.8 million metric tons (17.2 billion pounds) of hydrogen are produced in the United States today, enough to power 20-30 million cars or 5-8 million homes. Nearly all of this hydrogen is used by industry in refining, treating metals, and processing

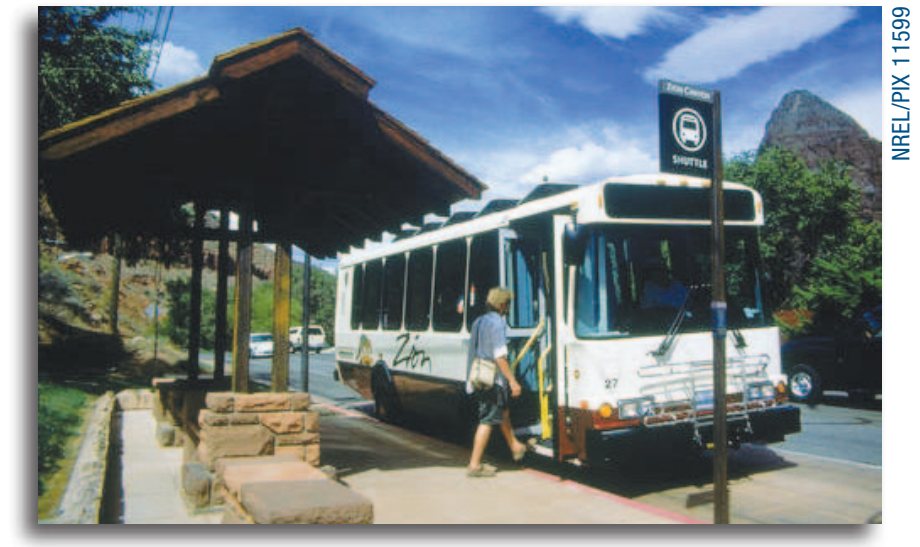

Propane powered shuttle bus in Zion National Park

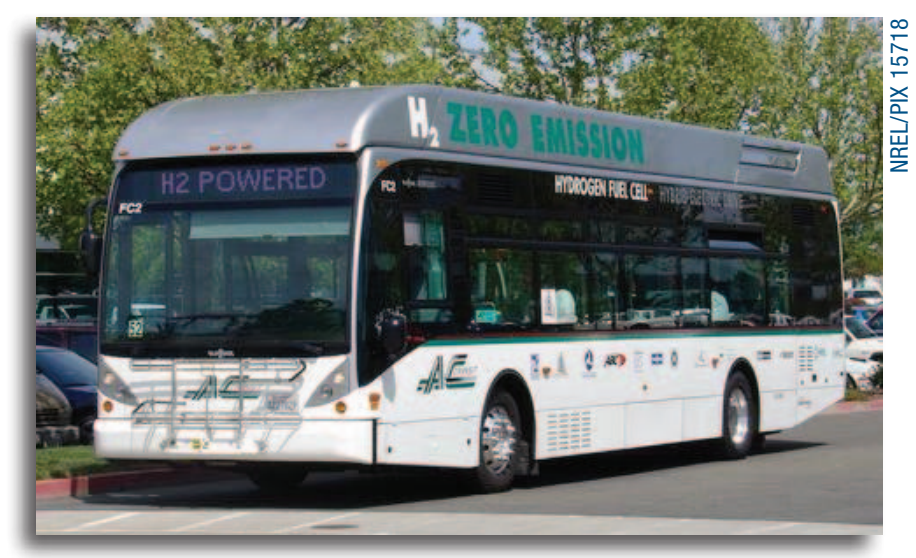

AC Transit's Hydrogen Fuel Cell-Hybrid Electric Drive Bus

foods. Most of this hydrogen is produced in just three states: California, Louisiana, and Texas (www.eia.doe.gov). Almost all of the hydrogen used is "captive," that is, consumed at the refinery or chemical plant where it is produced. Nevertheless, a safe and reliable hydrogen distribution network has been developed over the years, consisting of liquid hydrogen delivery trucks, gaseous hydrogen tube trailers, and dedicated gaseous hydrogen pipelines. Worldwide, there are over $800 \mathrm{~km}$ of hydrogen pipelines, including $225 \mathrm{~km}$ in the Ruhr Valley of Germany that have operated safely since 1938, and over 200 $\mathrm{km}$ of hydrogen pipeline in the United States, primarily in the Texas Gulf Coast area. Both liquid and gaseous hydrogen are distributed throughout the United States in hundreds of tanker trucks and tube trailers. (www.hydrogensociety.net) 
Basic Properties of Hydrogen, Methane, and Propane

\begin{tabular}{|c|c|c|c|}
\hline Gas Properties: & Hydrogen & Methane & Propane \\
\hline Chemical Formula & $\mathrm{H}_{2}$ & $\mathrm{CH}_{4}$ & $\mathrm{C}_{3} \mathrm{H}_{8}$ \\
\hline Molecular Weight & 2.016 & 16.04 & 44.097 \\
\hline Gas Density $\left(\mathrm{kg} / \mathrm{m}^{3}\right) @ \mathrm{STP}$ & 0.0808 & 0.643 & 1.767 \\
\hline Diffusivity (m²/sec) x 105 & 6.11 & 1.60 & 1.00 \\
\hline \multicolumn{4}{|l|}{ Combustion Properties: } \\
\hline Stoichiometric Fuel Volume Fraction \% & $29.5 \%$ & $9.48 \%$ & $4.03 \%$ \\
\hline Lower Heating Value $\left(\mathrm{MJ} / \mathrm{m}^{3}\right)$ & 9.9 & 32.6 & 81.2 \\
\hline Lower Heating Value (MJ/kg) & 118.8 & 50.0 & 46.35 \\
\hline Adiabatic Flame Temperature (K) & 2380 & 2226 & 2267 \\
\hline $\begin{array}{r}\text { Flammability Limits (Volume \%) } \\
\text { Lean Limit: } \\
\text { Rich Limit: }\end{array}$ & $\begin{array}{c}4 \% \\
75 \% \\
\end{array}$ & $\begin{array}{l}5.3 \% \\
15 \%\end{array}$ & $\begin{array}{l}2.2 \% \\
9.5 \%\end{array}$ \\
\hline Max. Flame Velocity $(\mathrm{m} / \mathrm{sec})$ & 3.06 & 0.39 & 0.45 \\
\hline Min. Ignition Temperature $(\mathrm{K})^{1}$ & 845 & 905 & 766 \\
\hline Min. Ignition Energy $\left(10^{-5} \mathrm{~J}\right)^{1}$ & 2.0 & 33 & 30.5 \\
\hline \multicolumn{4}{|l|}{ Storage Conditions: } \\
\hline Tank Type & Cylinder & Cylinder & Barbecue \\
\hline Volume (liters) & 49 & 49 & 21 \\
\hline Pressure (psi) ${ }^{2}$ & $34 \mathrm{MPa}$ & $17 \mathrm{MPa}$ & $1.6 \mathrm{MPa}$ \\
\hline Phase & Gas & Gas & Liquid \\
\hline Mass $(\mathrm{kg})$ & 1.35 & 5.36 & 0.61 \\
\hline
\end{tabular}

\section{Ignition and Combustion}

If there is a brief leak, hydrogen, being more buoyant, will rise more rapidly than either propane or methane vapor and will quickly disperse. A rapid dispersion rate is probably hydrogen's greatest safety asset in an outdoor environment, although wind and the escape velocity from a high-pressure tank may have more influence on the size of a flammable hydrogen cloud. Indoors, high dispersion rates can be both an asset, in the sense that a small leak will rapidly mix with air and stay below the lean flammability limit, and a potential liability — in a larger leak the expanding gas cloud is more likely to reach ignition sources.

The wide flammability range of hydrogen-air mixtures compared to the other fuels is a disadvantage. For example, hydrogen can ignite when the mixture is $50 \%$ hydrogen (with air), whereas methane or propane at the same fuel-air mixture cannot. Since the fuel concentration in air builds up from zero in most accidents with brief releases, ignition is most likely to occur when the fuel concentration first reaches the lean flammability limit. The lean flammability limit for hydrogen, while slightly lower than methane, is twice that of propane.
For example, propane can ignite when the mixture is $3 \%$ propane, whereas hydrogen or methane at the same fuel-air mixture will not ignite.

Once ignited, the adiabatic flame temperatures of hydrogen, methane, and propane differ very little in stoichiometric mixtures with air. The hazards related to high flame temperatures are almost the same for all of these fuels. The emissivity of a flame influences the total flux of heat radiated. The low flame emissivity of hydrogen reduces the heat transferred by radiation to objects near the flame and reduces the risks of secondary ignitions and burns. In other words, hydrogen flames radiate less heat than hydrocarbon-based fuels. Most accidental hydrocarbon flames, such as those from propane, natural gas, and gasoline, also contain soot that increases the amount of heat radiated.

A hydrogen flame is invisible in daylight and emits a low level of thermal radiation. Even if location is known, the envelope of the flame is not always easily distinguishable. In the hydrogen industry, fixed and portable optical detectors are widely used to detect hydrogen fires. 


\section{Deflagration and Detonation}

During combustion, flames can propagate through a flammable fuel-air mixture as either a deflagration or a detonation, depending on a complex interaction among factors such as the composition of the gas mixture, the ignition source and energy, the geometry of the surroundings, and the degree of confinement of the mixture (Beauvais et al. 1993). Deflagration, or simple combustion, is propagated through the flammable mixture by heat transfer and transfer of free radicals to the reactant gases ahead of the flame front at subsonic velocities. In a detonation, energy liberated in combustion is transmitted to the unburned layers of the fuel mixture by means of shock waves and propagates at supersonic velocities in the order of several $\mathrm{km} / \mathrm{sec}$ relative to the uncombusted mixture. Deflagrations and detonations in totally or partially confined areas constitute the most serious safety problem in using combustible gases.

The physical damage from an expanding flame front depends on its burning velocity, defined as the velocity of the advancing flame with respect to the unburned gas mixture ahead of it.

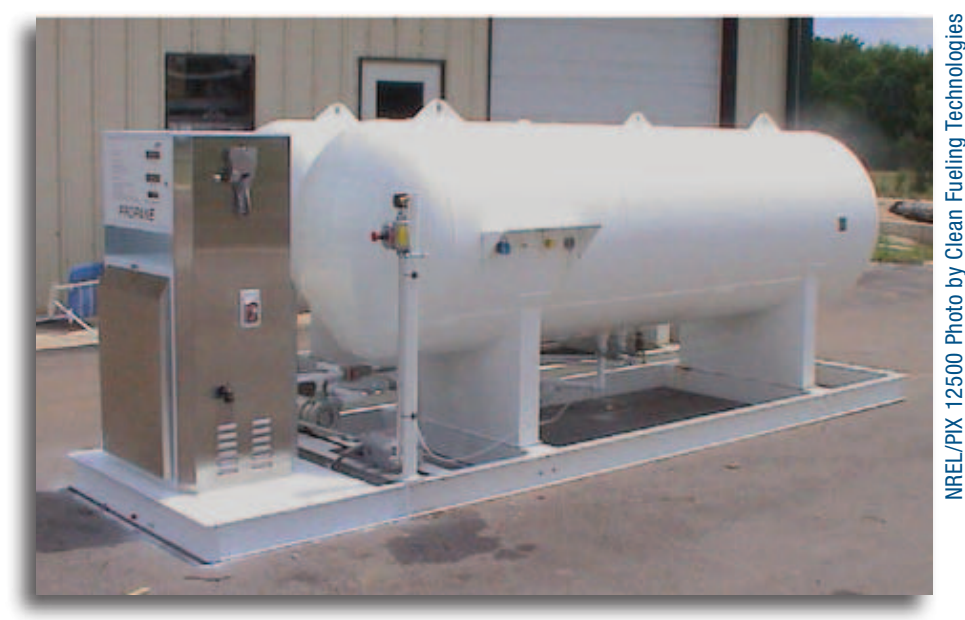

Propane tank on a movable skid.

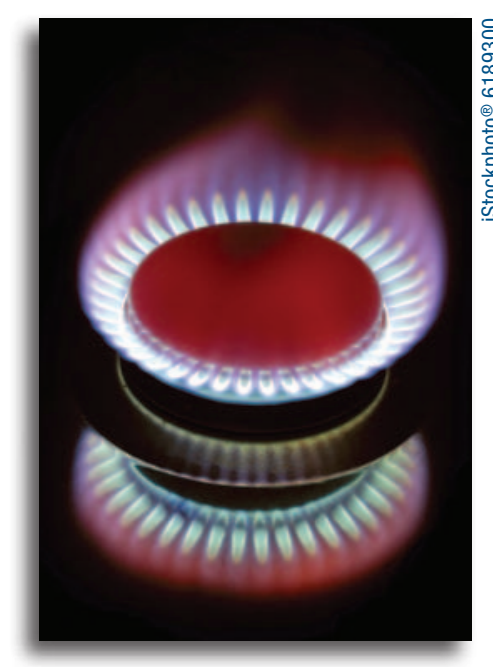

Propane Flame

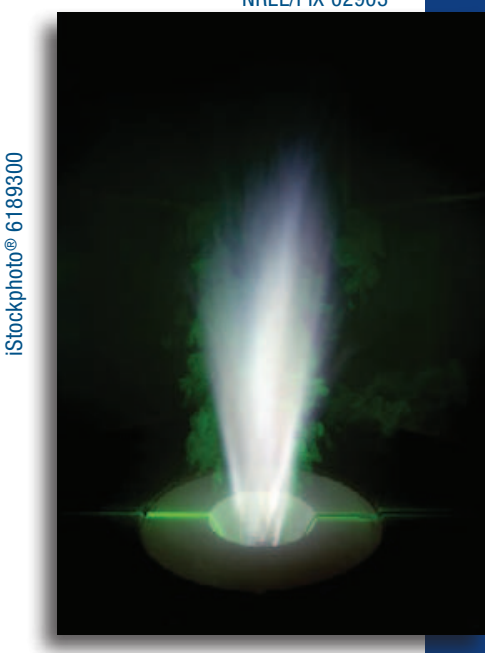

Hydrogen Flame
The maximum burning velocity of hydrogen-air mixtures is about eight times greater than for methane-air and propane-air mixtures and occurs at about $40 \mathrm{vol} \%$ hydrogen in air. The high burning velocity of hydrogen is an indication of its high explosive potential and the difficulty of confining or arresting hydrogen flames and explosions. A hydrogen flame is much more likely to progress to a more widespread deflagration or even to a detonation than are methane or propane flames, all else being equal. However, the likelihood of a detonation also depends on the exact fuel/air ratio, the temperature, and, particularly, the geometry of the confined space.

Overpressures and high temperatures caused by deflagrations are the main hazards of accidentally ignited fuel-air mixtures. Generally, existing boundary conditions determine the amount of over-pressure. In unconfined areas, the flame speed remains low, and little physical damage from large overpressure is possible. It is very unlikely that hydrogen would explode in an outdoor accident with normal ignition sources. Unconfined hydrogen-air mixtures do not detonate unless the ignition source delivers considerable ignition energy in the form of shock waves. A very high-energy source, such as a lightning strike or a chemical explosive, would likely be necessary to detonate a hydrogen gas cloud. 
In summary, a direct detonation is likely only when there is a coincidence of sufficient hydrogen accumulation and a high-energy ignition source. In confined areas, the storage and use of hydrogen pose hazards of both deflagration and detonation, as well as the transition of a deflagration to a detonation. Both of these processes depend on the flame velocity and on the conditions necessary to accelerate flame velocity. A confined deflagration can cause an explosion if the pressure and volume limits of a containment vessel are exceeded. The hazards of both deflagration and detonation of hydrogen can be addressed with proper design, engineering, and operation - as with any fuel used in confined areas.

\section{For More Information}

U.S. Department of Energy's Office of Energy Efficiency and Renewable Energy Hydrogen Fuel Cells and Infrastructure Technologies Program: http://www.eere.energy. gov/hydrogenandfuelcells/codes/.

U.S. Department of Energy's Hydrogen Program: http://www.hydrogen.energy.gov/ safety.html.

American Institute of Aeronautics and Astronautics, Guide to Safety of Hydrogen and Hydrogen Systems, ANSI/AIAA G-095-2004.

Beauvais, R., F. Mayinger, and G. Strube, Turbulent Flame Acceleration-Mechanisms and Significance for Safety Considerations, in Hydrogen Energy Progress IX, Vol. 2, Series IX, Proceedings of the 9th World Hydrogen Energy Conference, 22-25 June 1992, Paris, France, International Association for Hydrogen Energy, 1993.

National Aeronautics and Space Administration, Office of Mission Assurance, Safety Standards for Hydrogen and Hydrogen Systems, Washington, DC, February 1997.

National Hydrogen Association. Web site contains information on hydrogen safety and applications. http://www.hydrogenassociation.org/

National Propane Gas Association. Web site contains information on propane safety and applications. http://www.npga.org/i4a/pages/index.cfm?pageid=1

www.hydrogensociety.net/hydrogen_safety_issues.htm A Web site that contains information on hydrogen safety and an updated electronic version of the Sourcebook for Hydrogen Applications.

http://hydrogendoedev.nrel.gov/biblio_database.html A bibliographic database that provides references to reports, articles, books, and other resources for information on hydrogen safety as it relates to production, storage, distribution, and use.

Have a basic question about hydrogen or fuel cell technologies?

Need printed copies of documents?

Call the Energy Efficiency and Renewable Energy (EERE) Information Center at 877-EEREINF(0) / 877-337-3463 or submit your question or request online at www.eere.energy.gov/ informationcenter

Increase Your H2IQ!

Visit www.hydrogen.energy.gov

Prepared by NREL, a national laboratory of the U.S. Department of Energy, Office of Energy Efficiency and Renewable Energy, operated by the Alliance for Sustainable Energy, LLC. 